\section{A relapse case of acute necrotizing esophagitis}

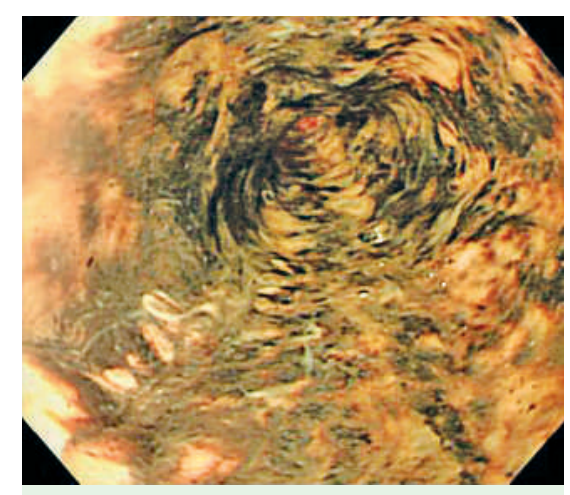

Fig. 1 Endoscopy revealed a black-appearing esophageal mucosa extending from the proximal two thirds of the esophagus to the cardia.

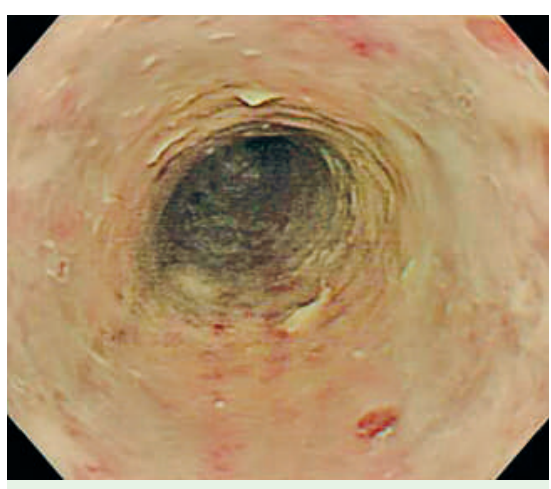

Fig. 2 After 6 days of treatment, the esophageal surface was diffusely covered with whitish exudates.

Acute necrotizing esophagitis (ANE) is a severe form of acute esophagitis that appears dark black in color ("black esophagus") at endoscopy due to mucosal necrosis [1]. ANE is an uncommon condition of unknown etiology. Grudell et al. reported that among 52 cases of ANE, seven cases involved massive gastroesophageal reflux [2]. As gastroesophageal reflux is one of the proposed causes of ANE [3,4], treatment generally includes administration of a proton pump inhibitor (PPI).

A 67-year-old man complained of vomiting and chest pain 5 days after surgery for a vitreous hemorrhage. The patient had a history of diabetes mellitus, hypertension, hyperlipidaemia, and angina pectoris. Endoscopy revealed a black-appearing esophageal mucosa extending from the proximal two thirds of the esophagus to the cardia ( $\bullet$ Fig. 1 ). After 6 days of

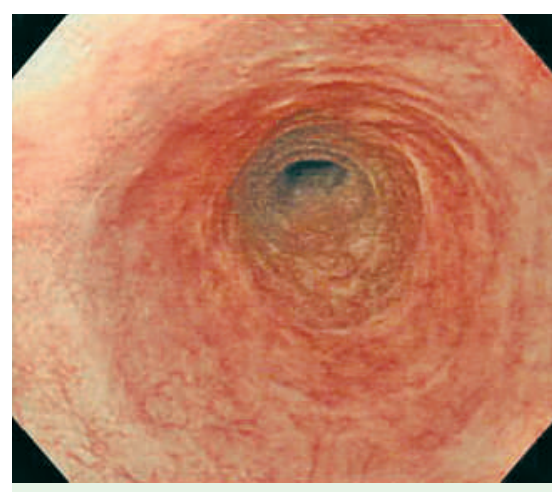

Fig. 3 By continuing to take rabeplazole for 4 months after release from hospital, the patient was cured of esophagitis.

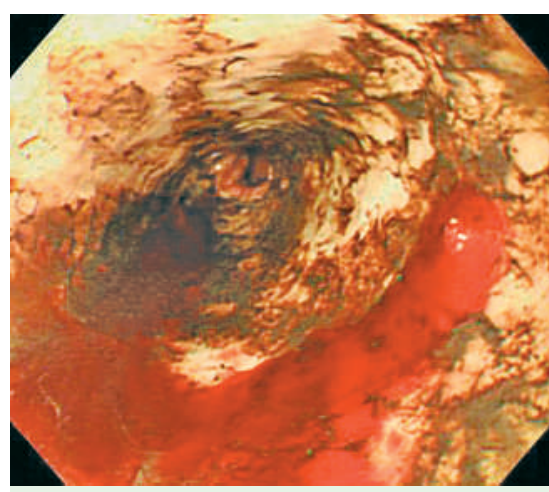

Fig. 4 The patient returned 37 days after finishing the rabeplazole treatment, and endoscopy revealed a reoccurrence of the black-appearing esophageal mucosa and whitish exudates, as well as mucosal bleeding.

treatment that included oral nutritional rest for 1 week and rabeplazole $(20 \mathrm{mg} /$ day), the mucosal surface was diffusely covered with whitish exudates ( $\bullet$ Fig. 2 ), and biopsy specimens consisted of necrotic debris. By continuing to take rabeplazole for 4 months after release from hospital, the patient was cured of esophagitis (๑ Fig. 3). However, 37 days after finishing the rabeplazole treatment, the patient returned due to recurring vomiting and chest pain. Endoscopy revealed a reoccurrence of the black-appearing esophageal mucosa and whitish exudates, as well as mucosal bleeding ( $\odot$ Fig. 4). Upon reestablishment of the treatment described previously, the relapsed ANE improved considerably within 3 weeks. With continued administration of rabeplazole, the ANE has not relapsed.
To our knowledge, this is the first reported case of a relapse of ANE [2,5]. In this case, relapse may have been associated with acid backflow, and we hypothesize that if the patient were to discontinue the PPI, he would experience another relapse.

Endoscopy_UCTN_Code_CCL_1AB_2AC_3AD

K. Tanaka ${ }^{1}$, H. Toyoda ${ }^{1}$, Y. Hamada ${ }^{2}$, M. Aoki², R. Kosaka², T. Noda², M. Katsurahara², M. Nakamura², K. Ninomiya ${ }^{2}$, H. Inoue ${ }^{2}$, I. Imoto ${ }^{1}$, Y. Takei ${ }^{2}$

1 Department of Endoscopic Medicine, Mie University School of Medicine, Tsu, Japan

2 Department of Gastroenterology and Hepatology, Mie University School of Medicine, Tsu, Japan

\section{References}

1 Goldenberg SP, Wain SL, Marignani P. Acute necrotizing esophagitis. Gastroenterology 1990; 98: 493-496

2 Grudell AB, Mueller PS, Viggiano TR. Black esophagus: report of six cases and review of the literature, 1963 -2003. Dis Esophagus 2006; 19: $105-110$

3 Katsinelos P, Pilpilidis I, Dimiropoulos S et al. Black esophagus induced by severe vomiting in a healthy young man. Surg Endosc 2003; $17: 521$

4 Reichart M, Busch OR, Bruno MJ et al. Black esophagus: a view in the dark. Dis Esophagus 2000; 13: $311-313$

5 Augusto F, Fernandes V, Cremers MI et al. Acute necrotizing esophagitis: a large retrospective case series. Endoscopy 2004; 36: $411-415$

Bibliography

DOI $10.1055 / \mathrm{s}-2007-966789$

Endoscopy 2007; 39: E305

(c) Georg Thieme Verlag KG Stuttgart · New York . ISSN 0013-726X

Corresponding author

\section{K. Tanaka, MD}

Department of Endoscopic Medicine

Mie University School of Medicine

2-174 Edobashi

Tsu

Mie

514-8507 Japan

Fax: + 81-59-231-5200

kyosuket@qa2.so-net.ne.jp 